\title{
WORK-RELATED DEPRESSION AND ASSOCIATED FACTORS IN A SHOE MANUFACTURING FACTORY IN HAIPHONG CITY, VIETNAM
}

\author{
KHUE PHAM MINH
}

Haiphong University of Medicine and Pharmacy, Haiphong, Vietnam

Faculty of Public Health

\begin{abstract}
Objectives: To determine the prevalence and associated factors of work-related depression among the employees of a shoe manufacturing factory in Haiphong City, Vietnam. Material and Methods: We carried out this cross-sectional study among 420 workers in 2012 in Le Lai II Shoe Manufacturing Factory in Haiphong City, Vietnam using Karasek's Job Content Questionnaire (JCQ) and the Diagnostic and Statistical Manual of Mental Disorders, 4th Edition (DSM IV) tool for measuring depression. Results: The study results show that a relatively high proportion of workers $(20.7 \%)$ belongs to the high-strain group based on Karasek's model. The prevalence of work-related depression among workers was relatively high (18.8\%). The factors associated with depression at work were high psychological demand (adjusted $\mathrm{OR}=3.0,95 \%$ CI: 1.1-8.3), low social support (adjusted OR = 4.7, 95\% CI: 1.2-12.8), inadequate work protection materials $(\mathrm{OR}=4.1,95 \% \mathrm{CI}: 2.2-10.1)$ and work absenteeism (OR $=6.2,95 \%$ CI: 2.5-18.9). Conclusions: Strengthening the social support network (involving supervisors and co-workers), reducing psychological job demand and assuring work protection materials at the workplace may highly facilitate reducing work-related depression.
\end{abstract}

Key words:

Work-related depression, Shoe manufacturing factory, Karasek's Job Content Questionnaire, Job Strain Model, Vietnam

\section{INTRODUCTION}

Job strain is defined by a series of reactions that occur when workers are faced with a disparity between demands at work and their knowledge, skills and aptitudes [1], while work-related depression is a clinical illness which is characterized by a combination of symptoms that interfere with a person's ability to work, sleep, study, eat, and enjoy once-pleasurable activities [2]. However, job strain can lead to various mental and physical disorders, such as depression, metabolic disorders, hypertension, angina pectoris and musculoskeletal disorders [1].
Depressed and stressed individuals have by $70 \%$ and $46 \%$ higher risk of developing illnesses and generating health expenditures, respectively [3]. These conditions also have an impact on enterprises due to the diminution in performance by stressed workers, absenteeism and increased staff turnover, with even additional costs resulting from a greater risk of accidents at work [1,4]. It is estimated that $50-70 \%$ of workers in developing countries (compared with $30 \%$ in industrialized countries) are forced to work in poor, in terms of ergonomics, working conditions. Most at risk are miners, farmers, fishermen, loggers, workers in the clothing manufacturing industry and

Received: March 24, 2014. Accepted: July 18, 2014

Corresponding author: K. Pham Minh, Haiphong University of Medicine and Pharmacy, Faculty of Public Health, 72A, Nguyen Binh Khiem, Ngo Quyen, Haiphong, Vietnam (e-mail: pmkhue@hpmu.edu.vn). 
health sector employees [3,4]. Low labor costs, easy supply of leather and a tradition of shoe making allowed shoe manufacturing industries to move to developing countries. Vietnam is becoming the largest footwear exporter after China [5]. Shoe manufacturing is one of the industrial sectors in the country that have shown sustained growth and recruited at least 2.5 millions of workers yearly, of which $80 \%$ are females. However, insufficient attention has been given to job factors such as job insecurity, physical exertion, chemical exposure and organizational hazards [6,7]. Studies all over the world have shown that depression, anxiety, and stress are a significant problem among blue collar workers [8-11]. More and more studies explore the relationship between psychosocial job factors and depression and stress [12-14]. Among the psychosocial job factors, 3 dimensions of the Job Demand-Control-Support [15] model of job stress - psychological job demand, job control and social support - are being widely used to explore this relationship. In Vietnam, no study has documented the prevalence of mental issues such as depression or stress and their relationships with psychosocial job factors in shoe manufacturing workers. This is a very serious omission. Therefore, the aim of this study is to determine the prevalence of workrelated depression and associated factors among workers in a large shoe manufacturing factory in Haiphong City.

\section{MATERIAL AND METHODS}

\section{Study design}

A cross-sectional study was designed to determine the prevalence of job strain and work-related depression and associated factors among workers in Le Lai II shoe factory in Haiphong.

\section{Sample size}

Sample size calculation was based on the $13 \%$ prevalence of work-related depression among employees in another study [16]. The power of the study was established at $80 \%$ with an $\alpha$ value of 0.05 . The calculated sample size was 385 workers needed to be included in the study. To prevent non-responded subjects, we planned to ask 430 workers for consent in order to achieve interviewing at least 385 workers in the study.

\section{Recruitment of study subjects}

We developed specific inclusion and exclusion criteria for our study subjects. The inclusion criteria were as follows:

- age between 18 and 55 years,

- working in the factory for at least 1 year,

- consent obtained to participate into the study.

The reason for choosing the 1-year threshold is that we expected to measure the impact of working conditions and factory organization on the mental patterns of the workers. The exclusion criterion was a diagnosis of any psychiatric illness. Le Lai II shoe factory has in total 1700 workers. Among them, 1500 are directly dealing with manufacturing shoes and 1200 of them met the inclusion criteria. We used a simple random table to draw 430 workers to be included in the study.

\section{Research instruments and data collection}

Data were collected through 4 questionnaires administered to the participants:

- a socio-demographic questionnaire,

- an instrument that measures job strain (JCQ-V),

- a questionnaire on absenteeism and workers' feelings about work conditions,

- the depression component of DSM IV.

The instrument measuring job strain (named JCQ-V) is the Karasek's Job Content Questionnaire (JCQ-K) that had been translated and validated from the English version into Vietnamese in an earlier study by Hoang Thi Giang et al. [17].

JCQ-K is a questionnaire-based instrument designed to measure the content of a work task. It contains 5 scales: psychological demand (job demand), decision latitude 
(job control), social support, physical demand, and job insecurity. Job demand can be described as a psychological stressor in the work environment, such as having to complete much work and working under time pressure. Job control consists of 2 components, namely "decision authority" (opportunity to make decisions concerning the job) and "skill discretion" (amount of skills used in the job). Social support also consists of two components co-workers' and supervisors' support. Physical demand is measured by the physical effort necessary to accomplish the task, while job insecurity is measured by job steadiness, job security, and future layoff. Four job conditions might result from different combinations of job demand and job control - active, passive, low strain, and high strain - according to Karasek's job strain model $[15,18]$.

The questionnaire on absenteeism contained 6 items whose construction was inspired by the book "Absenteeism: tools and methods for action" of the French National Agency for the Improvement of Working Conditions [19]. Five items assess absenteeism over the last 1 month (30 days): number of absences, total number of days of absence, causes of absences, absenteeism forecasts due to working conditions and the desire to change the job or workstation.

The DSM-IV depression component is a diagnostic tool developed by the American Psychiatry Association that is widely used in Vietnam [20,21]. This depression component contains 9 criteria for diagnosing depression (e.g., problems with sleeping, appetite), which are evaluated (presence or absence) over a 2-week period. According to the guidelines related to this tool, participants should be considered at risk for a depression diagnosis if they answered positively for 5 criteria out of 9 depressive symptoms. In this study, the addition of participants' answers for each clinical symptom was calculated ( 0 - absence, 1 presence) and expressed as an equivalent score of depressive symptoms (minimum: 0, maximum: 9).

Workers were also asked about their perceived work conditions and work protection using a questionnaire build and validated by the Department of Occupational Health at Haiphong University of Medicine and Pharmacy, which was used in several Vietnamese occupational health studies $[22,23]$. This questionnaire contained 7 questions asking the workers to rate their level of satisfaction of their work conditions (4 questions) and protection (3 questions) on 3 levels ( 0 - bad/inadequate, 1 - acceptable, 2 - good/ adequate). The general perceived work condition was good when the sum score was $>4$ and the general perceived work protection was adequate when the sum score was $>3$.

\section{Statistical analysis}

Data entry and analysis were done using the Statistical Program for Social Science (SPSS) Version 15.0. Means \pm standard deviations $(\mathrm{M} \pm \mathrm{SD})$ for continuous variables and frequencies and percentages for categorical variables were calculated for socio-demographic characteristics and occupational characteristics. Depression was treated as a dichotomous binary outcome - those above the median were considered as depressed and those below the median as non-depressed. The associations between depression and socio-demographic characteristics and psychosocial job factors were examined by multiple logistic regressions. The level of significance was set at the $p$ value of less than 0.05 . Multiple logistic regressions were checked for fitness using Hosmer-Lemeshow's goodness-of-fit test. All analyses were carried out in the Faculty of Public Health, Haiphong University of Medicine and Pharmacy, Haiphong, Vietnam.

The research protocol had been evaluated and approved by Haiphong University of Medicine and Pharmacy Institutional Review Board.

\section{RESULTS}

We successfully interviewed 420 workers in the factory. Table 1 shows that female workers represented a proportion 4 times higher than male workers $(77.9 \%$ vs. $22.1 \%$ ); most of them were young (nearly $75 \%$ 
Table 1. Socio-demographic characteristics of the study group

\begin{tabular}{|c|c|c|}
\hline \multirow{2}{*}{ Variable } & \multicolumn{2}{|c|}{$\begin{array}{l}\text { Respondents } \\
(\mathrm{N}=420)\end{array}$} \\
\hline & $\mathrm{n}$ & $\%$ \\
\hline \multicolumn{3}{|l|}{ Sex } \\
\hline female & 327 & 77.9 \\
\hline male & 93 & 22.1 \\
\hline \multicolumn{3}{|c|}{$\begin{array}{l}\text { Age (years) } \\
\qquad(\mathrm{M} \pm \mathrm{SD}=34.36 \pm 8.1)\end{array}$} \\
\hline$<20$ & 60 & 14.3 \\
\hline 20-29 & 138 & 32.9 \\
\hline $30-39$ & 114 & 27.1 \\
\hline $40-49$ & 98 & 23.3 \\
\hline$\geq 50$ & 10 & 2.4 \\
\hline \multicolumn{3}{|l|}{ Marital status } \\
\hline married & 289 & 68.8 \\
\hline single/divorced & 131 & 31.2 \\
\hline \multicolumn{3}{|l|}{ Education level } \\
\hline primary school & 1 & 0.2 \\
\hline secondary school & 92 & 21.9 \\
\hline high school & 327 & 77.9 \\
\hline
\end{tabular}

under 40 years old), nearly $80 \%$ had high school education level.

Table 2 shows that the average time of work per week was $55.5 \mathrm{~h}$; $68.3 \%$ subjects had worked for this factory for less than 5 years; $13.1 \%$ worked in shifts; $72.6 \%$ often or always used automated machines; $50 \%$ were absent at least 1 day during the last month. Most of them were absent 1-2 times during the last month and usually 1 day each time.

The prevalence of job strain is shown in Table 3. A relatively high proportion of workers (87/420) (20.7\%) belongs to the high-strain group. More than half of workers felt that they had a low-strain job (with low job demand and high decision latitude) and 33 (7.9\%) felt that they had a passive job (low job demand and low decision latitude).
Table 2. Occupational characteristics of the study group

\begin{tabular}{|c|c|c|}
\hline \multirow{2}{*}{ Variable } & \multicolumn{2}{|c|}{$\begin{array}{l}\text { Respondents } \\
(\mathrm{N}=420)\end{array}$} \\
\hline & $\mathrm{M} \pm \mathrm{SD}$ & $\mathrm{n}(\%)$ \\
\hline Work per week (h) & $55.5 \pm 14.0$ & \\
\hline $\begin{array}{l}\text { Total duration of } \\
\text { employment (years) }\end{array}$ & $5.7 \pm 4.8$ & \\
\hline \multicolumn{3}{|l|}{$\begin{array}{l}\text { Duration of employment } \\
\text { (years) }\end{array}$} \\
\hline $1-4$ & & $287(68.3)$ \\
\hline $5-9$ & & $50(11.9)$ \\
\hline$\geq 10$ & & $83(19.8)$ \\
\hline \multicolumn{3}{|l|}{ Shift work } \\
\hline yes & & $55(13.1)$ \\
\hline no & & $365(86.9)$ \\
\hline \multicolumn{3}{|l|}{$\begin{array}{l}\text { Absenteeism (during last } \\
\text { month) }\end{array}$} \\
\hline no & & $211(50.2)$ \\
\hline $1-2$ days & & $134(31.9)$ \\
\hline$>2$ days & & $75(17.9)$ \\
\hline \multicolumn{3}{|l|}{$\begin{array}{l}\text { Using automated } \\
\text { machines }\end{array}$} \\
\hline not at all & & $40(9.5)$ \\
\hline occasionally & & $75(17.9)$ \\
\hline often & & $215(51.2)$ \\
\hline always & & $90(21.4)$ \\
\hline
\end{tabular}

M - mean; SD - standard deviation.

Table 4 shows the prevalence of depression in 420 workers at the level of $18.8 \%$ (79/420). A higher proportion (23/87) $(26.4 \%)$ of workers in the high-strain group experienced depression compared to those who are not in the highstrain group (56/333) (16.8\%). The difference is statistically significant $(\mathrm{p}<0.05)$.

Table 5 shows the results of the multiple logistic regression analysis of depression in 420 shoe manufacturing workers. The factors associated with workrelated depression among shoe manufacturing workers in univariate analysis were high psychological 
Table 3. Prevalence of job strain following Karasek's Model

\begin{tabular}{lccc}
\hline \multirow{2}{*}{ Job demand } & \multicolumn{3}{c}{ Job decision latitude } \\
& low & high & total \\
\cline { 2 - 4 } & high strain & active & $141(33.6)$ \\
High & $87(20.7)$ & $54(12.9)$ & \\
& passive & low strain & $279(66.4)$ \\
Low & $33(7.9)$ & $246(58.6)$ & \\
& $120(28.6)$ & $300(71.4)$ & $420(100.0)$ \\
\hline
\end{tabular}

Table 4. Prevalence of depression (DSM IV) and its association with job strain

\begin{tabular}{lcccc}
\hline \multirow{2}{*}{ Depression } & \multicolumn{3}{c}{$\begin{array}{c}\text { High strain } \\
\text { (stress at work) } \\
\end{array}$} & \multicolumn{3}{c}{$[\mathrm{n}(\%)]$} & \multirow{2}{*}{$\mathrm{p}$} \\
\cline { 2 - 4 } & yes & no & total & \\
\hline Yes & $23(26.4)$ & $56(16.8)$ & $79(18.8)$ & 0.041 \\
No & $64(73.6)$ & $277(83.2)$ & $341(81.2)$ & \\
Total & $87(20.7)$ & $333(79.3)$ & $420(100.0)$ & \\
\hline
\end{tabular}

demand $(\mathrm{OR}=1.9,95 \%$ CI: $1.5-6.1)$, low and moderate social support $(\mathrm{OR}=2.6,95 \% \mathrm{CI}: 1.4-18.2$; $\mathrm{OR}=1.4,95 \% \mathrm{CI}: 1.3-15.1$, respectively), marital status $(\mathrm{OR}=2.6,95 \% \mathrm{CI}: 1.2-6.5$ for those who were married compared to those who were single or divorced), educational level (OR $=3.2,95 \% \mathrm{CI}$ : $1.1-6.2$ for those with a primary school level or lower compared to those who had a higher level of education), feeling of having inadequate work protection materials $(\mathrm{OR}=2.6,95 \% \mathrm{CI}: 1.0-5.3)$, absenteeism during the last month (OR $=4.4,95 \%$ CI: 2.1-9.3). However, when we performed multiple logistic regression, the factors that remained significantly associated with work-related depression were high psychological demand (adjusted OR $=3.0,95 \%$ CI: 1.1-8.3), low social support (adjusted $\mathrm{OR}=4.7,95 \% \mathrm{CI}: 1.2-12.8)$, feeling of inadequate work protection materials (OR $=4.1,95 \%$ CI: 2.2-10.1) and work absenteeism (OR $=6.2,95 \% \mathrm{CI}: 2.5-18.9)$.
Table 5. Associated factors of depression among shoe manufacturing workers

\begin{tabular}{|c|c|c|c|}
\hline Factor & $\begin{array}{c}\text { Crude OR }{ }^{\mathrm{a}} \\
\text { OR }(95 \% \mathrm{CI})\end{array}$ & $\begin{array}{l}\text { Adjusted OR }{ }^{\mathrm{b}} \\
\text { OR }(95 \% \mathrm{CI})\end{array}$ & $\mathrm{p}^{\mathrm{c}}$ \\
\hline \multicolumn{4}{|c|}{ Psychological demand } \\
\hline low & 1 & - & 0.047 \\
\hline high & $1.9(1.5-6.1)$ & $3.0(1.1-8.3)$ & \\
\hline \multicolumn{4}{|l|}{ Social support } \\
\hline high & 1 & - & \\
\hline moderate & $1.4(1.3-15.1)$ & $3.6(0.8-6.9)$ & 0.051 \\
\hline low & $2.6(1.4-18.2)$ & $4.7(1.2-12.8)$ & 0.032 \\
\hline \multicolumn{4}{|c|}{$x^{\prime}$} \\
\hline male & 1 & - & 0.111 \\
\hline female & $1.5(0.8-3.3)$ & $2.1(0.7-5.2)$ & \\
\hline \multicolumn{4}{|l|}{ Marital status } \\
\hline single/divorced & 1 & - & 0.088 \\
\hline married & $2.6(1.2-6.5)$ & $3.1(0.8-6.5)$ & \\
\hline \multicolumn{4}{|l|}{ Age (years) } \\
\hline$<40$ & 1 & - & 0.191 \\
\hline$\geq 40$ & $1.5(0.7-3.2)$ & $1.3(0.5-2.9)$ & \\
\hline \multicolumn{4}{|l|}{ Education level } \\
\hline $\begin{array}{l}\text { secondary school } \\
\text { and above }\end{array}$ & 1 & - & 0.082 \\
\hline $\begin{array}{l}\text { primary school } \\
\text { and lower }\end{array}$ & $3.2(1.1-6.2)$ & $4(0.8-6.5)$ & \\
\hline \multicolumn{4}{|c|}{$\begin{array}{l}\text { Duration of } \\
\text { employment (years) }\end{array}$} \\
\hline $1-9$ & 1 & - & 0.144 \\
\hline$\geq 10$ & $2.6(0.4-3.5)$ & $1.7(0.2-8.8)$ & \\
\hline \multicolumn{4}{|l|}{$\begin{array}{l}\text { Perceived work } \\
\text { conditions }\end{array}$} \\
\hline good & 1 & - & 0.191 \\
\hline bad & $1.5(0.5-4.4)$ & $2(0.6-4.5)$ & \\
\hline \multicolumn{4}{|c|}{$\begin{array}{l}\text { Perceived work } \\
\text { protection materials }\end{array}$} \\
\hline adequate & 1 & - & $<0.01$ \\
\hline inadequate & $2.6(1.0-5.3)$ & $4.1(2.2-10.1)$ & \\
\hline \multicolumn{4}{|l|}{ Work absenteeism } \\
\hline no & 1 & - & $<0.01$ \\
\hline yes & $4.4(2.1-9.3)$ & $6.2(2.5-18.9)$ & \\
\hline
\end{tabular}

${ }^{a}$ Univariate analysis; ${ }^{\mathrm{b}}$ multiple logistic regression; ${ }^{\mathrm{c}}$ likelihoodratio test.

$\mathrm{OR}$ - odds ratio; $\mathrm{CI}$ - confidence interval. $\alpha<0.05$. 


\section{DISCUSSION}

Karasek et al.[15,18] found that stressful work conditions were associated with impaired health. According to their research, the most stressful set of work conditions combines a low level of decision latitude (job control) - for example, having little control over the pacing of tasks or the allocation of resources - and having a highly psychologically demanding task, such as those that involve time pressure, deadlines, large workloads, and conflicting or heavy emotional demands. This "high-strain" combination is related to elevated risk for such negative health outcomes as coronary heart disease and depression. Presumably, the high level of demand creates arousal, and the inability to exert control leads to frustration. Mausner-Dorsch and Eaton [24] also found that high job strain was associated with greater prevalence of all forms of depression. They were able to evaluate the relation between occupational strain and depression with population-based data instead of with data from clinical or other selected populations.

We carried out this cross-sectional study among 420 shoe manufacturing workers in Le Lai II factory in Haiphong using DSM IV and JCQ-V tools that are validated in Vietnamese [17]. Among them, female workers represent a 4 times bigger proportion than male workers $(77.9 \%$ vs. 22.1\%), most of them are young (nearly $75 \%$ under 40 years old), and nearly $80 \%$ have high school education level. Table 3 presents that the prevalence of job strain was relatively high: $87 / 420$ workers $(20.7 \%)$ belong to the high-strain group. Table 4 shows the prevalence of depression in 420 workers at the level of $18.8 \%$ (79/420). A higher proportion (23/87) $(26.4 \%)$ of workers in the high-strain group experienced depression compared to those who are not in the high-strain group (56/333) $(16.8 \%)$. The difference is statistically significant $(\mathrm{p}<0.05)$. The results also confirm the importance of the demand-control model for depression by providing a theoretical framework to explain the relation between the psychosocial characteristics of the work environment and depression as a health outcome.
Table 2 shows that the average time of work per week is $55.5 \mathrm{~h}$; most subjects $(68.3 \%)$ had worked for this factory for less than 5 years; $13.1 \%$ work in shifts; $72.6 \%$ often or always use automated machines; and nearly $50 \%$ had been absent at least 1 day during the last month. In studying the relationship between an individual and work, special attention is usually given to work conditions - job characteristics, work surroundings - and organization of work, that are often hard to change. This is because it is technically, economically, and politically difficult, in practice, to influence the organization of work and to alter work conditions. The term 'work conditions' embraces physical work conditions (e.g., noise, temperature, lighting), chemical conditions (e.g., vapor, dust), and biological conditions (e.g., bacteria, viruses). The term 'organization of work' means the division of labor, mode of operation and work pace, and the way in which each worker is assigned a place and function.

The organization of work conflicts with the psychological functioning of an individual at every point, and it can be understood that depressive states may arise from the mode of organization of work. Clinical investigations have effectively demonstrated that assembly-line workers did not experience the same type of depression as office workers [25]. Furthermore, Hammen [26] has proposed that certain individuals may be vulnerable to some stressors more than others.

Based on Karasek's job strain model [9,15], high-strain workers would invariably experience adverse physical and psychological events such as, respectively, ischemic heart diseases and depression. In the present study, we found that the odds of having work-related depression were 3 times higher for high psychological demand (adjusted OR $=3,95 \%$ CI: 1.1-8.3) than low psychological demand, and for low social support they were 4.7 times higher (adjusted OR $=4.7,95 \%$ CI: $1.2-12.8$ ) than for high social support. Depression among workers was associated also with the feeling of inadequate materials of work protection 
(adjusted OR $=4.1,95 \%$ CI: 2.2-10.1) and work absenteeism (adjusted OR $=6.2,95 \%$ CI: $2.5-18.9$ ).

Lack of social support contributes to the development of job strain because opportunities to benefit from the positive (healthy) social contacts are reduced. Particularly with regard to 'people's work', which often implies intensive emotional experiences, social support from colleagues and superiors may help workers to cope effectively with these experiences. A meta-analytic study by Janssen et al. [27] provides evidence for the relationship existing between demands (workload) and lack of resources (limited social support) on the one hand, and emotional distress on the other. Social support from colleagues and supervisors can be very helpful in reducing and preventing emotional distress. Investigators have also found that depressed people have fewer supportive relationships and that depressionaffected persons perceive less support from the relationships that they do have [26]. As Blazer et al. [28] have speculated, depressed individuals may alienate those close to them because of their excessive demands for support a process that elicits rejection that in turn serves to intensify or maintain depression.

Another risk factor of depression among the workers was high psychological demand. The odds of having depression for high psychological demand were 3 times higher compared to low psychological demand (adjusted $\mathrm{OR}=3.0,95 \%$ CI: 1.0-8.8). However, there is some debate about whether the job demand dimension predicts health. In the Whitehall II (prospective cohort) study, a cohort of 6895 male and 3414 female London-based civil servants aged 35-55 years at baseline also showed that poor health was associated with lower job control, but not with high job demands [29].

In our study, the finding that the feeling of being provided with inadequate work protection materials was related to depression is difficult to be interpreted, but we think that the fact that the workers perform their tasks with the feeling of not being secured and safe at their workplace is a source of stressing perception, that affects the workers along with their time of work and may indirectly interact with their depression status. Another interesting factor that is associated with work-related depression is work absenteeism. The odds of having depression among workers who had been absent were 6.2 times higher compared to those who had not been absent during the last month. We think this pattern may rather be a consequence of work strain and depression leading to workers absenteeism.

A study conducted by Saini et al. [4] also proved that work-related depression was a product of stress and job dissatisfaction. Lack of social support and resources, little control and autonomy on the job, and unfair and overly demanding workloads and expectations could breed depression. Because of the strong association between the development of depression and the psychosocial work environment, businesses that contribute to negative employee affect may incur significant decreases in productivity, quality, and profit due to increases in absenteeism and turnover. This is consistent with the findings reported by Revicki et al. [16] that anger, depression, work stress, and job satisfaction were highly related. They also found a direct relationship between stress and depression and they concluded that employee emotions were closely linked to perceptions of social support and resource availability at the workplace.

\section{CONCLUSIONS}

The prevalence of work-related depression among shoe manufacturing workers was relatively high (18.8\%). A relatively high proportion of workers $(20.7 \%)$ belongs to the high-strain group based on the Karasek's Model. The factors associated with depression at work were high psychological demand (adjusted OR $=3.0$, 95\% CI: 1.1-8.3), low social support (adjusted OR $=4.7$, 95\% CI: 1.2-12.8), inadequate work protection materials (adjusted OR $=4.1,95 \%$ CI: $2.2-10.1$ ) and work 
absenteeism (adjusted OR $=6.2,95 \%$ CI: 2.5-18.9). Strengthening the social support network (involving supervisors and coworkers), reducing psychological job demand and assuring work protection materials at the workplace may facilitate reducing work-related depression.

\section{ACKNOWLEDGMENTS}

The corresponding author would like to thank Dr Nguyen Thi Thuy Linh and the Haiphong Medical University study team who have participated in data collection for this study; he would also like to dedicate special thanks to Le Lai II Factory Human Resources officers who have facilitated the access to the factory data and interviewing the workers.

\section{REFERENCES}

1. World Health Organization. [Work organizing and stress Protecting Workers' Health Series. No. 3]. Geneva: WHO; 2004 [cited 2013 Aug 24]. p. 1-18. Available from: http:// www.who.int/occupational_health/publications/en/pwh3f.pdf. French.

2. National Institute of Mental Health. Depression. 2013 [cited 2013 Aug 24]. Available from: http://www.nimh.nih.gov/ health/topics/depression/index.shtml.

3. World Health Organization. [Raising awareness of stress at work in developing countries. Protecting Workers' Health Series. No. 6]. Geneva: WHO; 2008 [cited 2013 Aug 24]. p. 1-20. Available from: www.who.int/occupational_health/publications/raisingawarenessofstress.pdf. French.

4. Saini NK, Agrawal S, Bhasin SK, Bhatia MS, Sharma AK. Prevalence of stress among resident doctors working in Medical Colleges of Delhi. Indian J Public Health. 2010; 54(4):219-23, http://dx.doi.org/10.4103/0019-557X.77266.

5. Hinh TD. Light manufacturing in Vietnam: Creating jobs and prosperity in a middle-income economy. Washington DC: The World Bank; 2014. p. 67-76, http://dx.doi.org/10.1596\% 2F978-1-4648-0034-4.
6. Dianat I, Salimi A. Working conditions of Iranian handsewn shoe workers and associations with musculoskeletal symptoms. Ergonomics. 2014;57(4):602-11.

7. Nijem K, Kristensen P, Al-Khatib A, Takrori F, Bjertness E. Prevalence of neuropsychiatric and mucous membrane irritation complaints among Palestinian shoe factory workers exposed to organic solvents and plastic compounds. Am J Ind Med. 2001;40(2):192-8.

8. Oleske DM, Neelakantan J, Andersson GB, Hinrichs BG, Lavender SA, Morrissey MJ, et al. Factors affecting recovery from work-related, low back disorders in autoworkers. Arch Phys Med Rehabil. 2004;85(8):1362-4.

9. Karasek R, Baker D, Marxer F, Ahlbom A, Theorell T. Job decision latitude, job demands, and cardiovascular disease: A prospective study of Swedish men. Am J Public Health. 1981;71(7):694-705.

10. Plaisier I, de Bruijn JG, de Graaf R, ten Have M, Beekman AT, Penninx BW. The contribution of working conditions and social support to the onset of depressive and anxiety disorders among male and female employees. Soc Sci Med. 2007;64(2):401-10.

11. Hwang WJ, Lee CY. Effect of psychosocial factors on metabolic syndrome in male and female blue-collar workers. Jpn J Nurs Sci. 2014;11(1):23-34, http://dx.doi.org/10.1111/ j.1742-7924.2012.00226.x.

12. Kim SA, Suh C, Park MH, Kim K, Lee CK, Son BC, et al. Effectiveness of a comprehensive stress management program to reduce work-related stress in a medium-sized enterprise. Ann Occup Environ Med. 2014;26(1):4, http://dx.doi. org/10.1186/2052-4374-26-4.

13. Pikhart H, Bobak M, Pajak A, Malyutina S, Kubinova R, Topor R, et al. Psychosocial factors at work and depression in three countries of Central and Eastern Europe. Soc Sci Med. 2004;58(8):1475-82, http://dx.doi.org/10.1016/S02779536(03)00350-2.

14. Wang J, Patten SB. Perceived work stress and major depression in the Canadian employed population, 20-49 years old. J Occup Health Psychol. 2001;6(4):283-9, http://dx.doi. org/10.1037/1076-8998.6.4.283. 
15. Karasek R. Job demands, job decision latitude, and mental strain: Implications for job redesign. Adm Sci Q. 1979;24(2):285-308.

16. Revicki DA, Whitley TW, Gallery ME. Organizational characteristics, perceived work stress, and depression in emergency medicine residents. Behav Med. 1993;19(2):74-81, http://dx.doi.org/10.1080/08964289.1993.9937568.

17. Hoang TG, Corbière M, Negrini A, Pham MK, Reinharz D, Hoang TG, et al. Validation of the Karasek-Job Content Questionnaire to measure job strain in Vietnam. Psychol Rep. 2013;113(2):363-79, http://dx.doi.org/10.2466/01.03. PR0.113x20z3.

18. Karasek R. Job content questionnaire and user's guide. Boston: Department of Work Environment, University of Massachusetts; 1997.

19. French National Agency for Enhancing Work Conditions. [Absenteism: Tools and methods to proceed]. Lyon: Anact; 2009. French.

20. Nguyen BD. Depression diagnosis results among students of a high school in Hanoi. Viet J Psychol. 2003;7:7-14.

21. Nguyen TTA. Symptoms of depression among patients aged 18-45 years treated in Danang General Hospital from October 2008 to March 2009. Danang: Danang University of Pedagogy; 2013. p. 72.

22. Vu DL, Pham MK. Work conditions and health issues among workers of a foreign investment garment company in Haiphong in 2012. Viet J Med. 2014;417(2):48-52.
23. Pham MK, Pham VH. Characteristics and risk factors of work-related accidents in Haiphong Port (2005-2010). J Preventive Med (Vietnam). 2014;4(154):61-5.

24. Mausner-Dorsch H, Eaton WW. Psychosocial work environment and depression: Epidemiologic assessment of the demand-control model. Am J Public Health. 2000; 90(11):1765-70, http://dx.doi.org/10.2105/AJPH.90.11.1765.

25. Kalimo R, Mejman T. Psychological and behavioural responses to stress at work. In: Kalimo R, Batawi MAE, Cooper CL, editors. Psychosocial factors at work and their relation to health. Geneva: World Health Organization; 1987. p. 23-96.

26. Hammen C. Depression. London: Routledge; 1997. p. 27-42.

27. Janssen PP, Jonge JD, Bakker AB. Specific determinants of intrinsic work motivation, burnout and turnover intentions: A study among nurses. J Adv Nurs. 1999;29(6):1360-9, http://dx.doi.org/10.1046/j.1365-2648.1999.01022.x.

28. Blazer DG, Kessler RC, McGonagle KA, Swartz MS. The prevalence and distribution of major depression in a national community sample: The National Comorbidity Survey. Am J Psychiatry. 1994;151(7):979-86.

29. Bosma H, Marmot MG, Hemingway H, Nicholson AC, Brunner E, Stansfeld SA. Low job control and risk of coronary heart disease in Whitehall II (prospective cohort) study. BMJ. 1997;314:558-65, http://dx.doi.org/10.1136/bmj. 314.7080.558.

This work is available in Open Access model and licensed under a Creative Commons Attribution-NonCommercial 3.0 Poland License - http://creativecommons.org/ licenses/by-nc/3.0/pl/deed.en. 